This article was downloaded by: [Australian National University]

On: 09 November 2011, At: 16:15

Publisher: Taylor \& Francis

Informa Ltd Registered in England and Wales Registered Number: 1072954 Registered office: Mortimer House, 37-41 Mortimer Street, London W1T 3J H, UK

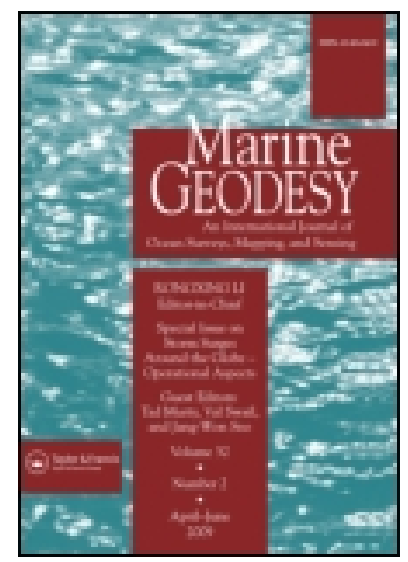

\title{
Marine Geodesy
}

Publication details, including instructions for authors and subscription information:

http:// www. tandfonline.com/loi/ umgd20

\section{Absolute Calibration in Bass Strait, Australia: TOPEX, J ason-1 and OSTM/ J ason-2}

\author{
Christopher Watson $^{a}$, Neil White ${ }^{b}$, J ohn Church ${ }^{b}$, Reed Burgette ${ }^{a}$ \\ , Paul Tregoning ${ }^{c} \&$ Richard Coleman ${ }^{d}$ \\ a Surveying and Spatial Science Group, School of Geography and \\ Environmental Studies, University of Tasmania, Tasmania, Australia \\ ${ }^{b}$ Centre for Australian Weather and Climate Research, Hobart, \\ Australia \\ ${ }^{\mathrm{C}}$ Research School of Earth Sciences, The Australian National \\ University, Canberra, Australia \\ d Institute for Marine and Antarctic Studies, University of Tasmania, \\ Tasmania, Australia
}

Available online: 22 Aug 2011

To cite this article: Christopher Watson, Neil White, J ohn Church, Reed Burgette, Paul Tregoning \& Richard Coleman (2011): Absolute Calibration in Bass Strait, Australia: TOPEX, J ason-1 and OSTM/ J ason-2, Marine Geodesy, 34:3-4, 242-260

To link to this article: http:// dx. doi.org/ 10.1080/ 01490419.2011.584834

\section{PLEASE SCROLL DOWN FOR ARTICLE}

Full terms and conditions of use: http://www.tandfonline.com/page/terms-and-conditions

This article may be used for research, teaching, and private study purposes. Any substantial or systematic reproduction, redistribution, reselling, loan, sub-licensing, systematic supply, or distribution in any form to anyone is expressly forbidden.

The publisher does not give any warranty express or implied or make any representation that the contents will be complete or accurate or up to date. The accuracy of any instructions, formulae, and drug doses should be independently verified with primary sources. The publisher shall not be liable for any loss, actions, claims, proceedings, demand, or costs or damages whatsoever or howsoever caused arising directly or indirectly in connection with or arising out of the use of this material. 


\title{
Absolute Calibration in Bass Strait, Australia: TOPEX, Jason-1 and OSTM/Jason-2
}

\author{
CHRISTOPHER WATSON, ${ }^{1}$ NEIL WHITE, ${ }^{2}$ JOHN CHURCH, ${ }^{2}$ \\ REED BURGETTE, ${ }^{1}$ PAUL TREGONING, ${ }^{3}$ \\ AND RICHARD COLEMAN ${ }^{4}$ \\ ${ }^{1}$ Surveying and Spatial Science Group, School of Geography and Environmental \\ Studies, University of Tasmania, Tasmania, Australia \\ ${ }^{2}$ Centre for Australian Weather and Climate Research, Hobart, Australia \\ ${ }^{3}$ Research School of Earth Sciences, The Australian National University, \\ Canberra, Australia \\ ${ }^{4}$ Institute for Marine and Antarctic Studies, University of Tasmania, \\ Tasmania, Australia
}

\begin{abstract}
Updated absolute bias estimates are presented from the Bass Strait calibration site (Australia) for the TOPEX/Poseidon (T/P), Jason-1 and the Ocean Surface Topography Mission (OSTM/Jason-2) altimeter missions. Results from the TOPEX side A and side $B$ data show biases insignificantly different from zero when assessed against our error budget $(-15 \pm 20 \mathrm{~mm}$, and $-6 \pm 18 \mathrm{~mm}$, respectively). Jason-1 shows a considerably higher absolute bias of $+93 \pm 15 \mathrm{~mm}$, indicating that the observed sea surface is higher (or the range shorter), than truth. For OSTM/Jason-2, the absolute bias is further increased to $+172 \pm 18 \mathrm{~mm}$ (determined from T/GDR data, cycles 001-079). Enhancements made to the Jason-1 and OSTM/Jason-2 microwave radiometer derived products for correcting path delays induced by the wet troposphere are shown to benefit the bias estimate at the Bass Strait site through the reduction of land contamination. We note small shifts to bias estimates when using the enhanced products, changing the biases by +11 and +3 mm for Jason-1 and OSTM/Jason-2, respectively. The significant, and as yet poorly understood, absolute biases observed for both Jason series altimeters reinforces the continued need for further investigation of the measurement systems and ongoing monitoring via in situ calibration sites.
\end{abstract}

Keywords Altimeter calibration, absolute bias, TOPEX, Jason-1, OSTM/Jason-2

\section{Introduction}

The first in the series of modern precision satellite altimeters, TOPEX/Poseidon (T/P), was launched in August 1992, followed by Jason-1 (December 2001) and the Ocean Surface Topography Mission (OSTM)/Jason-2 (June 2008). Central to the mission objectives of Jason-1 and OSTM/Jason-2 is the continuation of a unique climate record, the measurement of global and regional mean sea level and its change over time (Lambin et al.

Received 18 November 2010; accepted 30 March 2011.

Address correspondence to Christopher Watson, Surveying and Spatial Science Group, School of Geography and Environmental Studies, University of Tasmania, Private Bag 76, Hobart, Tasmania 7001, Australia. E-mail: cwatson@utas.edu.au 
2010). Combined with additional climate-related objectives, this imposes arguably the most stringent requirements on the altimetric measurement system as a whole. For this reason, the continued calibration and validation of the altimeter record is of utmost importance. Cross calibration of Jason-1 to T/P and OSTM/Jason-2 to Jason-1 has been greatly assisted through the use of an initial "formation flight" phase, with the pair of altimeters sampling essentially the same ocean and atmospheric conditions from an orbit separated by approximately 70 seconds and 55 seconds, respectively (Ménard et al. 2003; Lambin et al. 2010). Outside the formation flight period (approximately 7 months), calibration activities remain equally important to detect anomalous biases and drifts in the various system components (notably in, e.g., the radiometer (Zaouche et al. 2010)).

The inherent advantages in applying a multitechnique and geographically diverse set of calibration experiments has seen the development of two complementary calibration techniques for the assessment of altimeter sea surface height (SSH). First, in situ absolute calibration sites such as those at Harvest (Haines, Desai, and Born 2010), Corsica (Bonnefond et al. 2010a) and the focus of this paper, Bass Strait, provide essentially point-based measurements capable of independently quantifying the absolute bias of the altimeter SSH. Second, calibration using the global tide gauge network offers the ability to assess bias drift over time (Nerem et al. 2010).

The Bass Strait calibration site has been involved in the calibration effort since the launch of T/P (White et al. 1994; Watson et al. 2003, 2004). The site is the only one of its kind in the southern hemisphere and, unlike the sites at Harvest and Corsica, is located on a descending altimeter pass (pass 088). Bass Strait itself separates the island of Tasmania from the Australian mainland, with the calibration site located on the southwest of the Strait, near the city of Burnie. Bass Strait is a shallow body of water with typical depths of 60-80 $\mathrm{m}$ ( $\sim 51 \mathrm{~m}$ at the calibration site) (see Figure 1).

In this contribution, we detail the methodological and instrumental changes made at the Bass Strait site and provide updated results for the T/P, Jason-1 and OSTM/Jason-2 mission series. Readers are referred to previous works, Watson et al. $(2003,2004)$ and Watson (2005), for detailed descriptions of the prior methodological development at this site.

\section{Methodology}

The determination of absolute bias requires the direct comparison of altimeter and in situ $\mathrm{SSH}$ at a chosen comparison point (see Figure 2, Figure 3). As discussed by Bonnefond, Haines and Watson (2010b), the in situ SSH measurement can be achieved directly (e.g., observations from an oil platform or regular GPS buoy deployments) or indirectly (e.g., extrapolating from a coastal tide gauge using a precision marine geoid). The technique adopted at the Bass Strait site is unique and employs a combined strategy that is largely unchanged since the Watson et al. $(2003,2004)$ studies. For completeness, we briefly review the adopted methodology below and detail the specific processing throughout later sections.

\section{In situ Sea Surface Height}

To avoid the uncertainty associated in estimating a marine geoid, the Bass Strait site relies on the direct observation of SSH at the comparison point $\left(\mathrm{SSH}_{\text {In situ }}\right)$. In the absence of a fixed platform as used at the Harvest site (e.g., Haines et al. 2010), we observe SSH using a moored array of oceanographic instruments combined with episodic GPS buoy deployments 


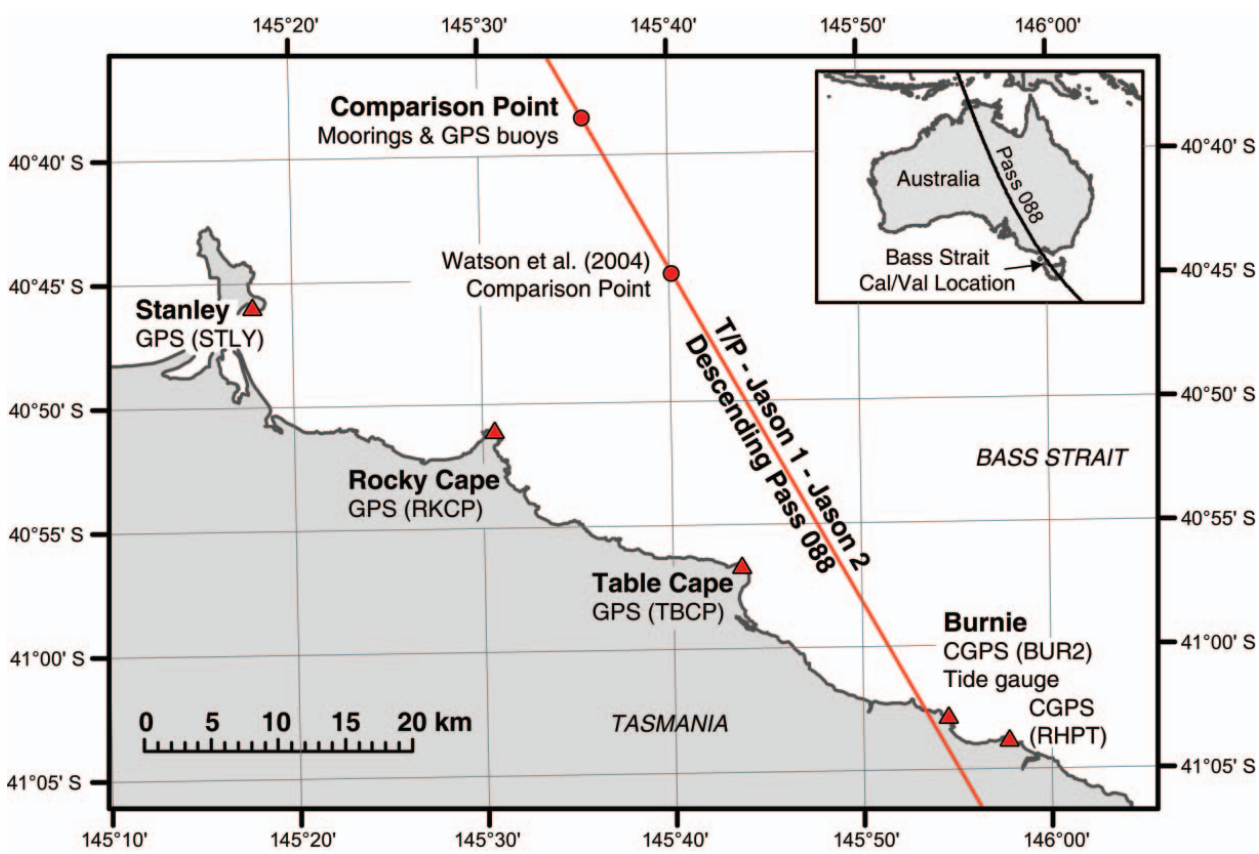

Figure 1. Bass Strait calibration site. Note the updated location of the comparison point in comparison to that used for the previous Watson et al. $(2003,2004)$ studies. (Figure available in color online)

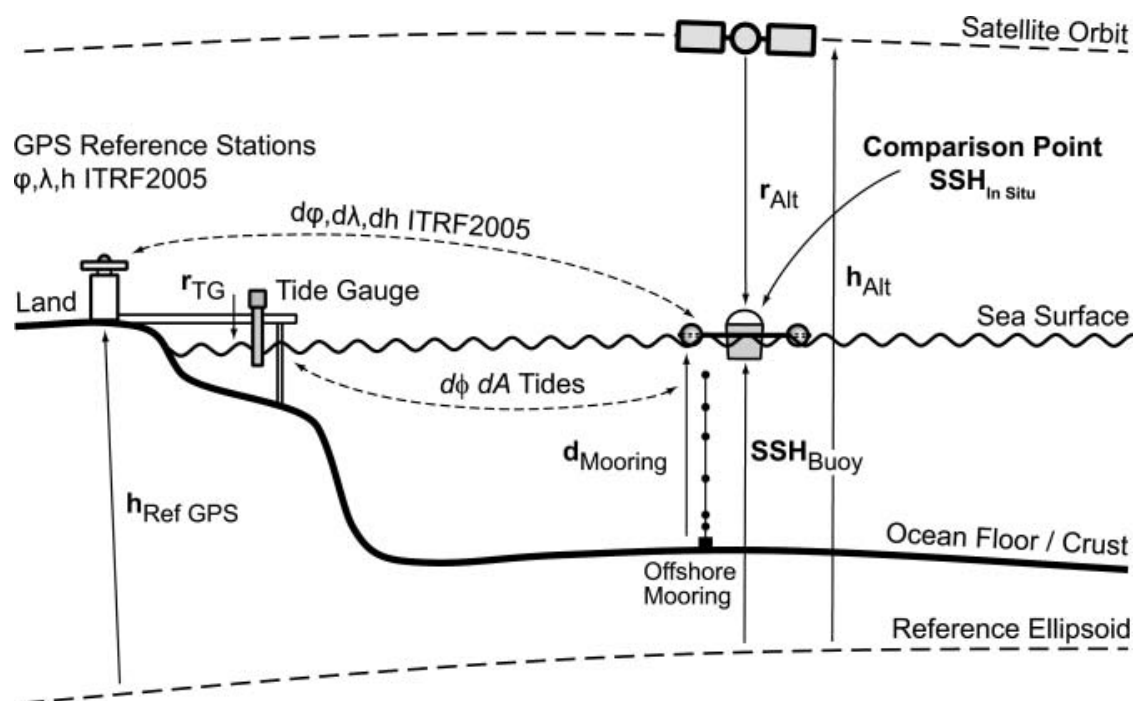

Figure 2. Calibration geometry adopted at the Bass Strait site. 


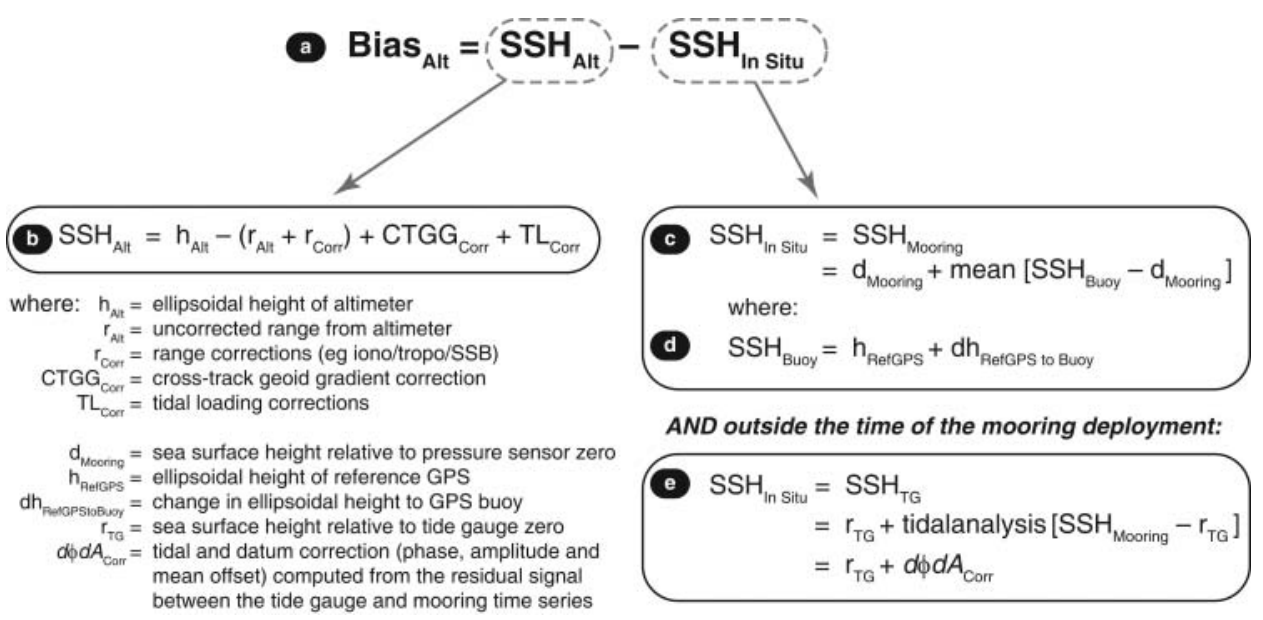

Figure 3. Absolute bias formulation.

(Figure 1). The moored instruments (pressure and temperature/salinity throughout the water column) yield a highly precise record of SSH, but in an arbitrary datum defined by the location of the pressure gauge zero with respect to the water surface ( $\mathrm{d}_{\text {Mooring }}$, Figure 2 . To define an absolute datum for the mooring record and enable computation of altimeter bias, GPS buoys are utilized (Figure 2). GPS buoys enable epoch-by-epoch determination of sea surface height $\left(\mathrm{SSH}_{\mathrm{Buoy}}\right)$ in an absolute reference frame that is directly comparable to the altimeter $\left(\mathrm{SSH}_{\mathrm{Alt}}\right)$. By computing a mean offset between the multiple GPS buoy records and a single mooring time series (i.e., $\mathrm{SSH}_{\text {Buoy }}$ vs $\mathrm{d}_{\text {Mooring }}$ ), the absolute datum of the mooring record can be obtained (Figure 3c). The precision and accuracy of the derived $\mathrm{SSH}_{\text {Mooring }}$ time series is therefore dependent not only on the precision of the oceanographic instruments but also on the number, duration and overall accuracy of GPS buoy deployments used to define the datum of the record.

At the Bass Strait site, the moored array of oceanographic instruments is typically deployed over a 12-month period, limiting the direct estimation of altimeter bias to that time interval. In order to extend the record of bias estimates, we use a modified indirect process to facilitate the use of a nearby coastal tide gauge for bias estimation. By comparing $\mathrm{SSH}_{\text {Mooring }}$ (recall this series has an absolute datum and is directly comparable to the altimeter) with the tide gauge record ( $\mathrm{r}_{\mathrm{TG}}$, arbitrary chart datum), a correction may be derived that includes a) the datum offset and b) the tidal differences (amplitude and phase) between the tide gauge and offshore comparison point (separated by $\sim 53 \mathrm{~km}$ in this case). A tidal analysis is undertaken on the difference time series between the concurrent $\mathrm{SSH}_{\text {Mooring }}$ and $\mathrm{r}_{\mathrm{TG}}$ data, to derive these corrections (Figure 3e). While the datum offset (i.e., the $\mathrm{ZO}$ constituent in the tidal analysis) is constant, the tidal component may be predicted forward or backward in time, thus enabling the correction of tide gauge data to the comparison point for all available observations at this tide gauge. This unique indirect process avoids computing a marine geoid (e.g., Bonnefond et al. 2010a) and allows bias computation across the complete altimetry record.

\section{Altimeter Sea Surface Height}

The methods used to determine the altimeter sea surface height $\left(\mathrm{SSH}_{\mathrm{Alt}}\right)$ at a chosen comparison point are largely identical between the dedicated absolute calibration sites (Figure 
$3 b)$. Altimeter orbit height $\left(\mathrm{h}_{\mathrm{Alt}}\right)$, range $\left(\mathrm{r}_{\mathrm{Alt}}\right)$, range correction $\left(\mathrm{r}_{\text {Corr }}\right)$ and loading correction $\left(\mathrm{TL}_{\mathrm{Corr}}\right)$ data $(1 \mathrm{~Hz})$ are extracted from the relevant mission Geophysical Data Record (GDR) and interpolated to derive $\mathrm{SSH}_{\mathrm{Alt}}$ at the comparison point. Unique to each calibration site is the cross-track geoid gradient $\left(\mathrm{CT}_{\mathrm{Corr}}\right)$ required to account for the sea surface slope between the altimeter ground track and comparison point (typically within $\pm 500 \mathrm{~m}$ for TOPEX, Jason-1 and OSTM/Jason-2 altimeters at this location). Following computation of $\mathrm{SSH}_{\mathrm{Alt}}$, the altimeter bias can be derived on a cycle-by-cycle basis (Figure 3a).

\section{Instrumentation}

\section{Tide Gauge and GPS Reference Network}

The tide gauge used at the Bass Strait calibration site is located in the industrial port of Burnie (Figure 4a). The gauge is an Aquatrak acoustic instrument that forms part of the Australian Baseline Sea Level Monitoring Project operated by the Australian Bureau of Meteorology's National Tidal Centre (NTC 2011). The gauge was commissioned in early September 1992 prior to the start of the TOPEX/Poseidon science mission (White et al. 1994). Local deformation of the tide gauge (and GPS) is monitored via regular conventional levelling surveys connecting the tide gauge to a regional network of tide gauge bench marks located throughout the port complex and extending inland to bedrock. With the exception of two anomalous events involving a) a knock from a tug boat in January 2007 and b) a collision with an adrift tug boat in storm conditions in July 2007 (at which times levelling was repeated to quantify vertical displacement), the local stability of the tide gauge is well known with no statistically significant deformation occurring (Geoscience Australia 2011). The gauge data are supplied at 6-minute intervals and are referenced to a single Chart Datum (i.e., all datum shifts such as those mentioned above are applied).

Co-located with the tide gauge are the continuously operating GPS (CGPS) sites BUR1/BUR2 (BUR1 ran until disruption of the site via tug boat in January 2007, the replacement, BUR2, commenced operation in March 2008). A bedrock CGPS site, RHPT (commencing December 2007), is located approximately $4.3 \mathrm{~km}$ to the east (Figure 1, Figure 4a). In addition to these CGPS sites, episodic GPS sites are operated along the coast to the west of Burnie to minimise baseline lengths in the kinematic processing of the GPS buoys.

\section{Moored Oceanographic Instruments}

At the offshore comparison point, two arrays of oceanographic instrumentation were moored in situ. Array A, deployed January 24, 2008, consisted of a precision pressure gauge (SBE26plus), deployed at approximately $50 \mathrm{~m}$ water depth. Array B, deployed adjacent to Array A and running simultaneously, consisted of a pressure gauge (SBE26plus), two Microcat SBE37 temperature and salinity sensors and two Aquadopp current meters (Figure 4b). Array B was retrieved, serviced and redeployed on July 4, 2008, to avoid fouling on the sensitive SBE37 instruments. Both arrays were retrieved on February 2, 2009 , yielding a combined $\sim 375$ day time series.

\section{GPS Buoys}

Fundamental to the adopted methodology is the determination of the absolute datum of the mooring time series using repeated episodic deployment of GPS buoys. The GPS buoys are 

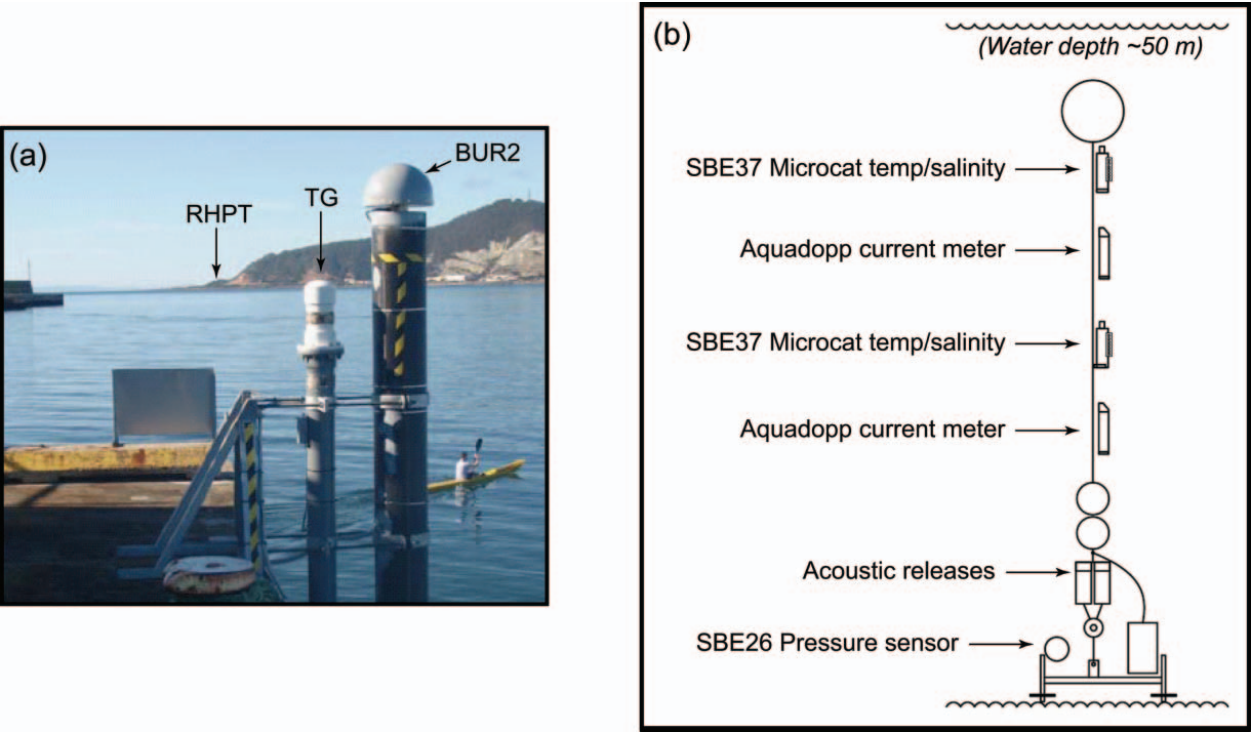

Figure 4. (a) Acoustic tide gauge and CGPS located at Burnie. GPS site BUR2 is co-located with the tide gauge, and site RHPT is $\sim 4.3 \mathrm{~km}$ away located on bedrock. (b) Moored oceanographic instruments used at the comparison point. (Figure available in color online)

not used to directly estimate the altimeter bias; rather they are deployed at the comparison point to constrain the datum of the mooring record. This is subsequently used for direct estimation of absolute bias or for deriving tidal and datum corrections for the coastal tide gauge which is subsequently used in the bias estimation process.

A limitation of the GPS buoys used in Watson et al. $(2003,2004)$ was the proximity of the antenna to the water surface (Figure 5a). Frequent GPS signal obstructions (and therefore loss of lock on one or more GPS satellites) occurred in rough conditions, complicating the analysis of the GPS observations. Given that the comparison point in this project was moved to a more exposed location (to avoid radiometer land contamination, [Figure 1], an updated MkIII GPS buoy design was developed (Figure 5b).
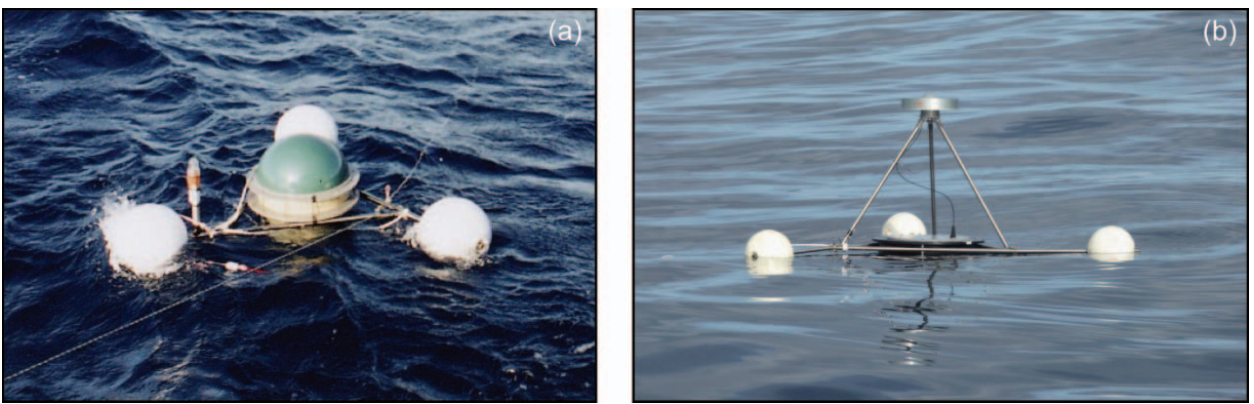

Figure 5. GPS buoy designs used at the Bass Strait site. (a) the MkII design as per Watson et al. (2003) and (b) the MkIII design as used in this study. (Figure available in color online) 
The MkIII design houses batteries and GPS receiver (Leica GX1230GG) in a central capsule, supported by three $300 \mathrm{~mm}$ diameter polystyrene floats on a stainless steel frame. The antenna (Leica AT504 choke ring) is elevated above the centre of the capsule, with the antenna reference point (ARP) $0.810 \mathrm{~m}$ above the mean water level. The raised antenna enables operation without a protective radome, minimizing any potential phase center variation effects (Watson 2005).

As per Watson et al. (2003), our strategy is to deploy a pair of GPS buoys at any one time, tethered horizontally $\sim 30-40 \mathrm{~m}$ from an anchored boat at the comparison point. The two buoys are kept $\sim 10 \mathrm{~m}$ apart on individual tethers to the boat. Deployments $1-4$ were of $\sim 8$ hours duration, and deployments $5-8$ were of $\sim 10$ hours duration.

\section{Processing}

\section{In situ Sea Surface Height}

Moored Oceanographic Instruments. Data from the year-long deployment of the SBE26plus pressure gauge (Array A) and two 6-month deployments of two Seabird SBE37 Microcat instruments (Array B) were used to derive a SSH time series for the duration of the mooring deployment $\left(\mathrm{d}_{\text {Mooring }}\right)$. The $\mathrm{d}_{\text {Mooring }}$ time series was computed by first subtracting the local atmospheric pressure from the pressure gauge readings (from Array A, 5-minute sampling) to give the pressure head of the water column. The atmospheric pressure time series (hourly samples) was obtained from the Burnie tide-gauge site, some $\sim 53 \mathrm{~km}$ along track from the mooring location. To account for any potential differential atmospheric pressure between the two sites, model data (with $5 \mathrm{~km}$ resolution) from the Australian Bureau of Meteorology's Limited Area Prediction System (LAPS) were utilized (Puri et al. 1998). The differential pressure obtained from the model was applied as a correction to the Burnie pressure time series. This correction had a range of $\sim 5 \mathrm{hPa}$ (standard deviation $0.75 \mathrm{hPa}$ ) and was indicative of the passage of pressure systems in the area in an eastward direction. The SBE26plus pressure gauge used for this deployment is quoted as having an absolute accuracy of $\sim 12 \mathrm{~mm}$, with repeatability of $\sim 5 \mathrm{~mm}$. A comparison of the year-long SBE26plus record (Array A) with the two shorter half-year records from Array B (an equivalently configured SBE26plus instrument) is consistent with this in that standard deviations derived from concurrent sections of the records were around 3-4 mm, and changes in measured pressure (translated to sea level equivalent) were +3 and $-8 \mathrm{~mm}$ over the 6-month (or longer) common period. Some of this cumulative drift may have been due to drift within the pressure sensors or one or both of the instruments settling over time.

A time series of density profiles (for use in computing the dynamic height) was calculated from the temperature and salinity data from the Seabird Microcat instruments on Array B (10-minute sampling interval). There were no significant changes in this time series resulting from the service and redeployment of the Array B sensors. The temperature sensors are quoted as having an absolute accuracy of $0.002 \mathrm{C}$ and a stability of 0.0002 $\mathrm{C}$ per month or better. The salinity output is quoted as having an accuracy of $0.003 \mathrm{psu}$ and a stability of 0.003 psu per month. Finally, the computed density profiles were used to convert the water-column pressures to depths $\left(\mathrm{d}_{\text {Mooring }}\right)$ on a 5-minute time base. We estimate the uncertainty associated with $\mathrm{d}_{\text {Mooring }}$ to be $12 \mathrm{~mm}$. This includes contributions from the pressure sensor $(5 \mathrm{~mm})$, estimation of the dynamic height $(5 \mathrm{~mm})$ and estimation of the overhead atmospheric pressure $(10 \mathrm{~mm})$. 


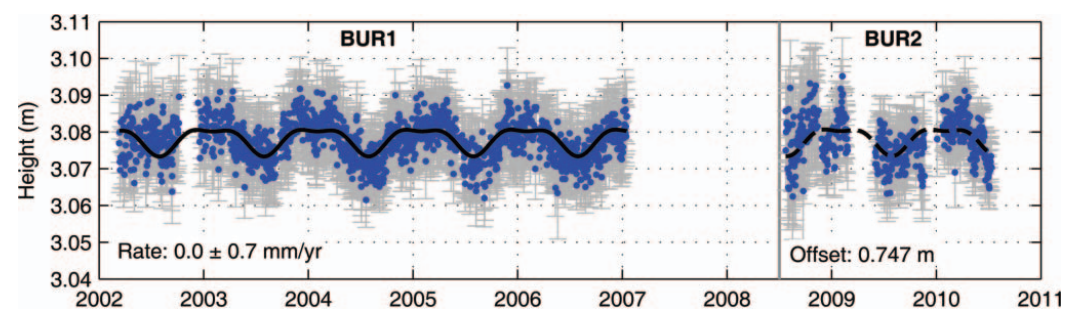

Figure 6. Vertical time series from the BUR1 and BUR2 CGPS sites. The black line (dashed over BUR2) includes offset, rate and solar annual and semi-annual periodic terms computed using only the BUR1 data. (Figure available in color online)

GPS Buoys and Reference Sites. As per Watson et al. (2004), there are two components to the GPS analysis at the Bass Strait site. First, GPS observations from the reference stations (Figure 1) are processed in order to derive mean site coordinates in a comparable reference frame to that used for the altimeter orbit determination (ITRF2005; Altamimi et al. 2005). We utilize the GAMIT/GLOBK analysis suite (Herring, King and McClusky 2008), processing all reference station data within a $\sim 50$ station global network using techniques discussed in Tregoning and Watson (2009). We apply integer ambiguity resolution across the network, utilise IERS2003 compliant tidal loadings, and use the ECMWF/VMF1 a priori zenith hydrostatic delays and mapping function. Analysis of the coordinate time series generated from this analysis for the CGPS sites at Burnie, BUR1 and BUR2 (Figure 1), provides information on the vertical stability of the tide gauge that is itself fundamental to the bias determination process (Figure 3). Using a combined time variable white and power law noise model (Williams 2008), we estimate the vertical velocity of BUR1 to be $0.0 \pm 0.7 \mathrm{~mm} / \mathrm{yr}$ (Figure 6). Given the short and fragmented BUR2 record (caused by early hardware related failures), we exclude BUR2 from the analysis of vertical velocity. The hypothesis that the vertical velocity is insignificantly different from zero is supported when assessing the tectonic setting of the Bass Strait site on the Australian plate. The closest long-running CGPS site is located in southern Tasmania near Hobart (site HOB2, $300 \mathrm{~km}$ from Burnie). Our analysis of the complete HOB2 record since 2000.0 yields a vertical velocity of $+0.3 \pm 0.5 \mathrm{~mm} / \mathrm{yr}$. Further, the nearest significant earthquakes originate from the Macquarie Ridge Complex, some $\sim 1500 \mathrm{~km}$ away along the Australian-Pacific plate boundary. The largest of these events coinciding with the space geodetic record was the 8.1 $\mathrm{M}_{\mathrm{w}}$ event occurring in December 2004, north of Macquarie Island. Small co-seismic deformations were observed in the horizontal coordinate components as far-field as Burnie, yet no co-seismic or post-seismic deformation has been observed in the vertical component (Watson et al. 2010). The source of the annual signal present in the BUR1 and BUR2 CGPS record (Figure 6) is unknown and under further investigation.

The second component of the GPS analysis involves the kinematic processing of the $1 \mathrm{~Hz}$ data from the episodic GPS buoy deployments. This analysis is undertaken using a multireference station approach (using the closest reference sites at STLY and RKCP, Figure 1) undertaken within the GrafNav suite (Novatel 2010). Sites STLY and RKCP are constrained to their ITRF2005 positions as determined in the previous analysis. Processing is undertaken in forward and reverse directions prior to smoothing and outputting a $1 \mathrm{~Hz}$ coordinate stream for each GPS buoy deployed. Following Watson et al. (2004), we filter the $1 \mathrm{~Hz}$ data stream using a 20-minute box car filter to produce $\mathrm{SSH}_{\text {Buoy }}$. These data are compared directly against the arbitrary $\mathrm{d}_{\text {Mooring }}$ time series in order to define the datum 

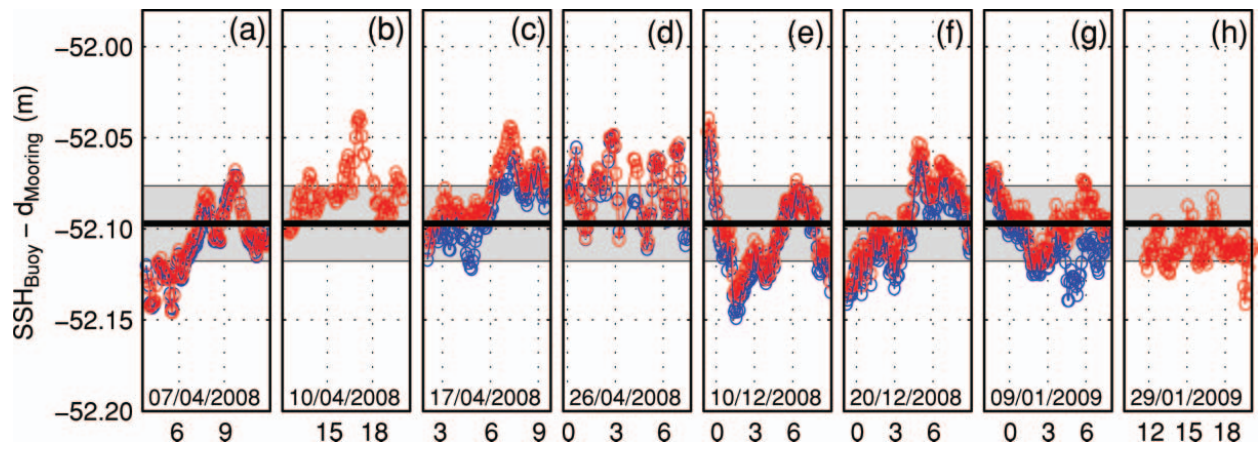

Figure 7. Residual time series $\left[\mathrm{SSH}_{\text {Buoy }}-\mathrm{d}_{\text {Mooring }}\right]$ from 8 deployments (two buoys for each deployment with the exception of b) and h). This series is used to define the datum of the $\mathrm{SSH}_{\text {Mooring }}$ series. The heavy bold line represents the mean (i.e., the datum offset required for $\mathrm{d}_{\text {Mooring }}$ ), the shaded grey region shows \pm 1 standard deviation $(21 \mathrm{~mm})$. Deployment commencement dates are provided. $\mathrm{X}$-axis labels are hours of UTC time. (Figure available in color online)

(Figure 7). The standard deviation of the $\mathrm{SSH}_{\text {Buoy }}-\mathrm{d}_{\text {Mooring }}$ residual, computed over the 8 deployments (undertaken over the yearly deployment of the mooring) is $21 \mathrm{~mm}$. As a result of the movement in the comparison point and the associated increase in baseline lengths, this variability has approximately doubled from the previous Watson et al. (2004) study. As a consequence, longer duration deployments were undertaken in this study to ensure this error contribution is minimised with an increased sample size (see error budget).

\section{Tide Gauge}

As previously discussed, we reduced the moored oceanographic instruments to derive

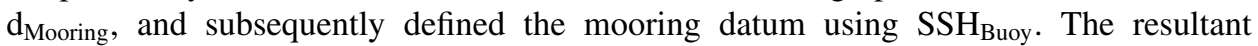
$\mathrm{SSH}_{\text {Mooring }}$ series was then used to derive a correction for datum and tidal differences with respect to the tide gauge. This correction effectively transforms the tide gauge data out to the comparison point, allowing cycle-by-cycle comparison with the altimeter over the duration of the much longer tide gauge record (commencing with the launch of T/P).

Following interpolation to a common time base, the 375 day $\left[\mathrm{SSH}_{\text {Mooring }}-\mathrm{r}_{\mathrm{TG}}\right.$ ] time series has an RMS of $\sim 98 \mathrm{~mm}$. This difference is dominated by tidal variations predominately at semi-diurnal frequencies and higher, with the dominant components at M2 (amplitude $126 \mathrm{~mm}$ ) and $\mathrm{N} 2$ (amplitude $30 \mathrm{~mm}$ ). Following the tidal analysis of the $\left[\mathrm{SSH}_{\mathrm{Mooring}}-\mathrm{r}_{\mathrm{TG}}\right]$ time series, the non tidal residual has an RMS of $27 \mathrm{~mm}$ (Figure 8).

A range of potential signals contribute to the variation observed in Figure 8, including measurement uncertainty in both the $\mathrm{d}_{\text {Mooring }}$ and $\mathrm{r}_{\mathrm{TG}}$ records; differential inverted barometer

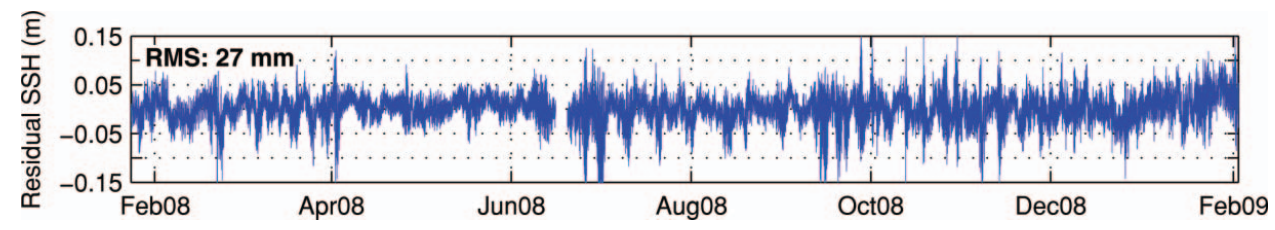

Figure 8. Nontidal residual computed from the $\mathrm{SSH}_{\text {Mooring }}-\mathrm{r}_{\mathrm{TG}}$ time series (note the mean has been removed). (Figure available in color online) 
response of the sea surface, wind or current induced changes to sea surface set-up; errors in the computation of the dynamic height included in $\mathrm{d}_{\text {Mooring }}$; settling of the mooring anchor into the sediment; unresolved temperature related effects within the tide gauge; and local episodic seiche-like phenomena affecting the tide gauge. Given the comparatively small magnitude of the residual variability $(27 \mathrm{~mm})$ and our inability to analytically or empirically predict many of the contributing signals mentioned above (outside of the period of the mooring deployment), we choose to apply just the datum offset and tidal correction to the raw tide gauge data. We filtered the resultant time series $\left(\mathrm{SSH}_{\mathrm{TG}}\right)$ using a low pass Butterworth filter with a half-power point at 90 minutes, eliminating the influence of any localised harbour effects. For the benefit of developing an error budget, we used the RMS of the residual shown in Figure 8 as a measure of precision of the $\mathrm{SSH}_{\mathrm{TG}}$ record. We conservatively estimated 20 days ( 2 altimeter cycles) as the decorrelation length of the residual series (Figure 8), in the preparation of our final error budget.

\section{Altimeter Sea Surface Height}

TOPEX/Poseidon. The data analysis for $\mathrm{T} / \mathrm{P}$ is limited to $1 \mathrm{~Hz}$ TOPEX range data extracted from the most recent MGDR-B release (Benada 1997). We update the orbit to use those of Lemoine et al. (2010) and apply standard corrections for spacecraft center-of-gravity and the influence of the dry troposphere. For the ionosphere correction, we use the mean of all GDR values between $39^{\circ} 48^{\prime} \mathrm{S}$ and $40^{\circ} 48^{\prime} \mathrm{S}$, noting that using other smoothers (e.g., as recommended in GDR manuals) makes negligible difference. For the wet troposphere, the issues associated with calibration of the TOPEX Microwave Radiometer (TMR) are well known (Brown et al. 2009). We maintain our approach used in Watson et al. (2004), recalculating the $18 \mathrm{GHz}$ brightness temperatures (Ruf 2000, 2002), and computing the wet troposphere correction from the brightness temperatures (Keihm, Janssen and Ruf 1995). We apply a further correction for the effects of the satellite yaw-steering mode ( $2.4 \mathrm{~mm}$ in sinusoidal yaw and $-1.4 \mathrm{~mm}$ for fixed yaw; Brown, Ruf and Keihm 2002). We do not consider the 15-hour thermal settling time as it does not affect pass 088 for the cycles used in this study (all yaw state transitions are more than 15 hours away). We address the interpolation of the TMR data to the comparison point in a later section. Finally, for the sea-state bias correction, we use the Chambers et al. (2003) model for side $\mathrm{A}$ and $\mathrm{B}$, and also provide comparison of bias estimates computed using the nominal MGDR-B SSB.

Jason-1 and OSTM/Jason-2. Data products used for Jason-1 and OSTM/Jason-2 are GDR$\mathrm{C}$ and T/GDR, respectively. We treat the ionosphere correction the same way for both datasets as per that discussed for the T/P MGDR data. The wet troposphere correction is used directly from the data product and, for comparison, we use a second radiometer product applied to both missions that has been enhanced for improved near-coast performance (Brown 2010). We differentiate between the different wet troposphere corrections based on the name of the radiometer, that is, TMR (Topex Microwave Radiometer on T/P), JMR (Jason Microwave Radiometer on Jason-1) and AMR (Advanced Microwave Radiometer on OSTM/Jason-2). To distinguish the "enhanced" coastal product, we prefix each with enhanced (enhanced JMR and enhanced AMR). The further treatment of these wet troposphere products is discussed below.

Radiometer Data Treatment and Computation of Altimeter SSH. It is well known that the wet troposphere correction derived from the TMR, JMR and AMR instruments is adversely 
affected in the coastal zone by land contamination (Brown 2010). This issue influences all the in situ absolute calibration sites given their proximity to the land (Bonnefond et al. 2010b). Constraints include logistical factors and (for sites such as Corsica and Bass Strait) the need to maintain relatively short GPS baseline lengths for precise processing of GPS data from floating platforms at the comparison point. At the Bass Strait calibration site, the effect of land contamination is clearly evident when inspecting the time series of brightness temperatures (and hence wet troposphere corrections) as the satellite travels on its descending pass over Bass Strait (Watson et al. 2004). In this study, to aid in the minimisation of this effect, we moved the comparison point seaward along the altimeter pass (Figure 1), trying to balance competing issues of land contamination versus minimizing GPS baseline length for the relative processing of the episodic GPS buoy deployments. Given it remains likely that this comparison point is still influenced by land contamination, we retain the method presented by Watson et al. (2004) to overcome the effect by linearly extrapolating the radiometer derived wet corrections over a $\sim 70 \mathrm{~km}$ window extending from $-39.9^{\circ} \mathrm{S}$ to $-40.45^{\circ} \mathrm{S}$ (Figure 9).

More importantly, tests reported by Watson et al. (2004) highlighted that the linear extrapolation outperformed a more simplistic mean value approach given the typical trend in wet delay signatures observed along pass 088 in this portion of Bass Strait. When using the enhanced radiometer products, the land contamination is largely mitigated at the comparison point, thereby potentially avoiding the requirement to linearly extrapolate (see, e.g., Figure 9b).

For computing $\mathrm{SSH}_{\mathrm{Alt}}$, the extrapolated wet corrections are used together with corrections for the solid earth tide, pole tide, and ocean loading taken directly from the GDR. The resultant $1 \mathrm{~Hz} \mathrm{SSH}$ data are linearly interpolated to the point of closest approach (PCA) to the comparison point. We apply a cross-track geoid gradient $(12 \pm 3 \mathrm{~mm} / \mathrm{km}$, updated from Watson et al. 2003, given the shift in comparison point) to finally derive $\mathrm{SSH}_{\mathrm{Alt}}$ at the comparison point. We remove clearly erroneous altimeter data at this stage (e.g., clear spurious jumps in the $1 \mathrm{~Hz}$ range correction fields) before computing the altimeter bias estimates.

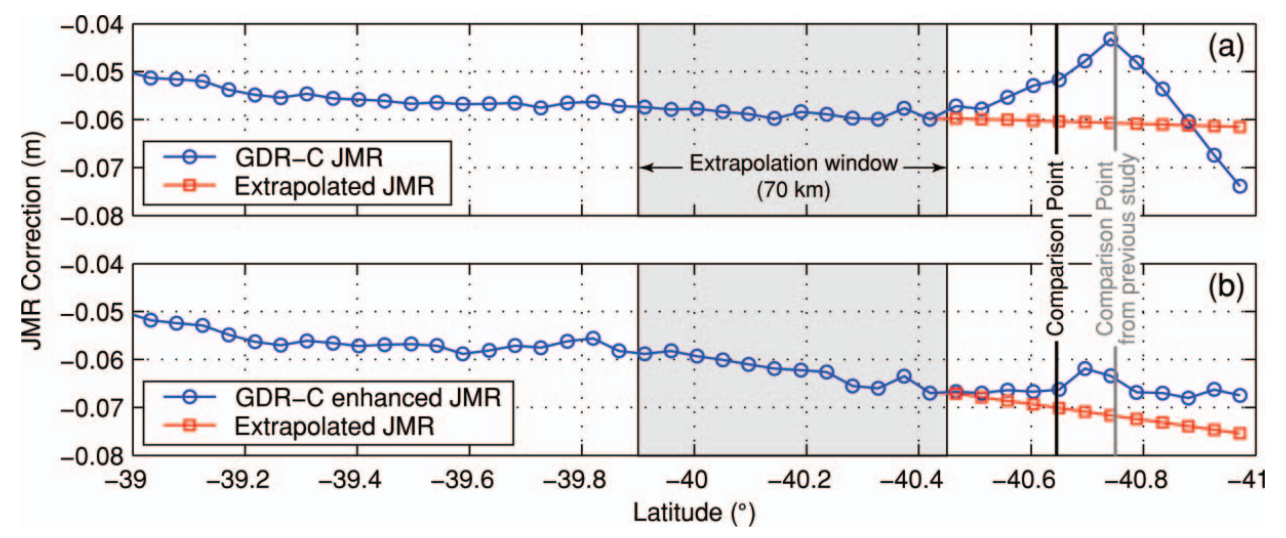

Figure 9. Example treatment of the radiometer derived wet troposphere correction (cycle 255) for (a) GDR-C JMR, and (b) the enhanced JMR product. The comparison point is $\sim 25 \mathrm{~km}$ from the closest land ( $\sim 52 \mathrm{~km}$ from the tide gauge along track). (Figure available in color online) 


\section{Error Budget}

The computation of realistic error bounds surrounding estimates of absolute bias is highly problematic given the systematic nature of many of the components in the closure equation (Figure 3). Following Watson et al. (2004), we update the error budget for the Bass Strait site, quantifying both time averaging and non-time averaging (systematic) error contributions. For cycle-by-cycle uncertainties from the altimeter, we maintain estimates from Watson et al. (2004) and adopt an equivalent value for OSTM/Jason-2 as for Jason-1. For the timeaveraging component of the $\mathrm{SSH}_{\text {In situ }}$ record, we recognize components from the tidally corrected tide gauge data $(27 \mathrm{~mm}$, taken from the residual shown in Figure 8, and from the $\mathrm{SSH}_{\text {Buoy }}$ data $\left(21 \mathrm{~mm}\right.$, representing the standard deviation of the $\mathrm{SSH}_{\text {Buoy }}-\mathrm{d}_{\text {Mooring }}$ series). While each of these contributions average with time, there is clear autocorrelation present in the respective time series. In the final bias uncertainty computation, we estimated conservatively that the tidally corrected tide gauge data can be considered independent after two altimeter cycles. For the $\mathrm{SSH}_{\text {Buoy }}$ contribution, this is only averaged over the $\sim 802$ samples (5-minute intervals) found in the $\mathrm{SSH}_{\text {Buoy }}-\mathrm{d}_{\text {Mooring }}$ record (Figure 7). We conservatively estimate independent estimates every 3 hours in the final uncertainty computation (i.e., $\mathrm{n}=$ 22). For the systematic, non-time averaging components, we maintain $10 \mathrm{~mm}$ for the possible systematic components in the GPS buoy processing (e.g., antenna height, method used for solving the tropospheric delay), and $10 \mathrm{~mm}$ for the reference station solution (Watson et al. 2004). Here we add the uncertainty associated with the vertical velocity at the tide gauge ( $\pm 0.7 \mathrm{~mm} / \mathrm{yr}$ relative to 2005 ) in order to scale the $10 \mathrm{~mm}$ contribution forward or backward in time to the midpoint of a specific series of altimeter bias estimates. Given the independence of the buoy and reference station related uncertainties, these values sum in quadrature. As indicated in Table 1, uncertainty estimates for absolute bias estimates for each mission have been computed, with typical values between \pm 16 and $20 \mathrm{~mm}$. We contend that these uncertainty estimates represent a realistic error bound that contrasts sharply against formal statistics computed directly from absolute bias time series (e.g., typical standard errors about the mean are approximately $\pm 2-4 \mathrm{~mm}$ ). It is also important to note that this error budget (pertaining to the absolute bias) is dominated by nontime-averaging contributions to the in situ absolute datum. These error contributions do not affect the uncertainty associated with relative bias between different instruments or missions at the Bass Strait site.

\section{Results and Discussion}

\section{Absolute Bias}

The principal absolute bias results for this paper span TOPEX side A (MGDR-B, cycles 001-235), TOPEX side B (MGDR-B cycles 236-365), Jason-1 (GDR-C, cycles 001-259) and all available data at the time of writing for OSTM/Jason-2 (T/GDR, cycles 001-079). To ease comparison between the various calibration sites, the results provided (Figure 10) include the bias estimate, standard error about the mean (assuming complete independence between cycles), standard deviation and number of samples. Note that the standard error about the mean (Figure 10) is purely a statistical measure of repeatability and does not include contributions from systematic components as reflected in the error budget discussed previously.

For TOPEX, we observe bias estimates of $-15 \pm 20 \mathrm{~mm}$ and $-6 \pm 18 \mathrm{~mm}$ for side $\mathrm{A}$ and $\mathrm{B}$, respectively, both insignificantly different from zero when assessed against the quoted error budget. When reverting to the MGDR-B SSB model, the bias estimates show 
Table 1

Error budget for the Bass Strait calibration site

Time averaging error contribution

Error (mm)

Altimeter SSH ( SSH $\left._{\text {Alt }}\right)$

- T/P SSH Alt $(*)$ :

- J-1 \& OSTM/J-2 $\mathrm{SSH}_{\mathrm{Alt}}\left(^{*}\right)$ :

In Situ SSH ( SSH $\left._{\text {In Situ }}\right)$

- Tidally corrected tide gauge data $\left(^{* *}\right) \quad 27$

- Contribution from $\mathrm{SSH}_{\text {Buoy }}\left({ }^{* * *}\right) \quad 21$

Non-time averaging error contribution:

Absolute Datum

- Reference station solution

- Contribution from vertical velocity $(\mathrm{mm} / \mathrm{yr})\left(^{\#}\right)$

- Kinematic solution (inc antenna ht and PCV)

-Total (RSS@2005):

TOTALS:

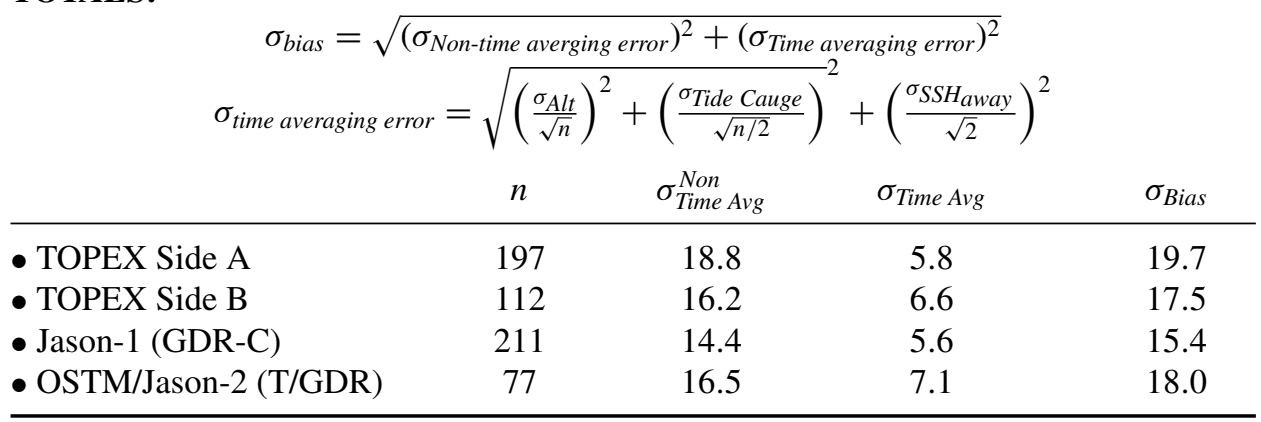

*Uncertainty is per over flight, based on $\mathrm{SWH}<1.5 \mathrm{~m}$. Assumed independent for each cycle.

${ }^{* *}$ Uncertainty is per overflight. Due to temporal correlation in $\left[\mathrm{SSH}_{\mathrm{Mooring}}-\mathrm{r}_{\mathrm{TG}}\right]$ series, assume independent estimate every two cycles.

*** Uncertainty is based on $\left[\mathrm{SSH}_{\text {Buoy }}-\mathrm{d}_{\text {Mooring }}\right]$ from 8 buoy deployments. Assuming independent estimates every 3 hours, $n=22$ in final computation.

\#Reflects additional uncertainty in reference station position as a function of time, relative to 2005.

slight changes to $-17 \mathrm{~mm}$ and $-15 \mathrm{~mm}$ (sides A and B). These results for TOPEX are consistent with those previously reported from the Harvest (Haines et al. 2010), Corsica (Bonnefond et al. 2010a) and Bass Strait (Watson 2005) calibration sites. Subtle differences in the estimates from the Bass Strait site are attributed to the movement to the new comparison point and subsequent redefinition of the datum, and a correction to the application of the across track gradient. When using the NASA POE orbit from the MGDR-B, we see a $15-17 \mathrm{~mm}$ increase in bias to $+0 \mathrm{~mm}$ and $+11 \mathrm{~mm}$ for sides $\mathrm{A}$ and $\mathrm{B}$, respectively $(-2$ $\mathrm{mm}$ and $+2 \mathrm{~mm}$ when using the MGDR-B SSB). Note that the standard errors about the mean of these various bias determinations are approximately $\pm 2-4 \mathrm{~mm}$.

Absolute bias estimates for Jason-1 $(+93 \pm 15 \mathrm{~mm})$ and OSTM/Jason-2 $(+172 \pm$ $18 \mathrm{~mm}$ ) are both significantly different from zero, indicating both of the Jason series of altimeters are observing short to the sea surface (corresponding, the observed sea surface is too high). Estimates for these missions are directly comparable with other calibration 


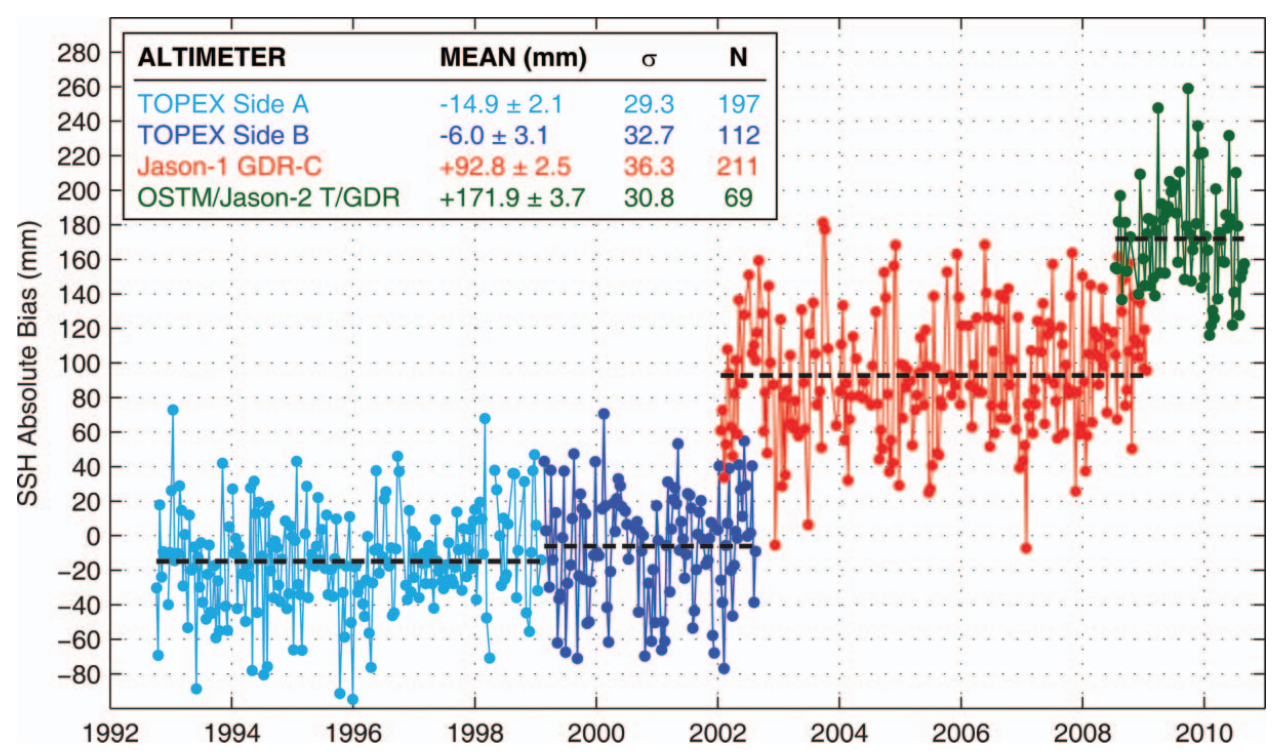

Figure 10. Absolute bias time series for TOPEX Side A (cycles 001-235), TOPEX Side B (cycles 236-365), Jason-1 (GDR-C, cycles 001-259) and OSTM/Jason-2 (T/GDR, cycles 001-079). For ease of comparison, the colour scheme has been adapted from Haines et al. (2010). Note the uncertainties reflect the standard error about the mean bias, and do not reflect the error budget. (Figure available in color online)

sites and show particularly close agreement to those from Harvest platform (+94 mm and $+178 \mathrm{~mm}$ ), agreeing to within the quoted standard errors about the mean. This level of agreement is not necessarily expected given the potential differences in wave climate between the two sites, and the potential dependence of absolute bias and sea state (see, e.g., Haines et al. 2010). At Bass Strait, the mean significant wave height is $\sim 1 \mathrm{~m}$, well under half the value at Harvest. It remains to be seen if such dependence can be detected when comparing results from different calibration sites given subtle variability in processing strategies and considerable variability in observational platforms.

As discussed in Haines et al. (2010), with recent clarification provided at the OSTST meeting in Lisbon (October 2010), a truncation error in the pulse repetition frequency (PRF) used on both Jason altimeters has been discovered that biases range observations. The PRF issue explains $\sim 120$ and $\sim 25 \mathrm{~mm}$ of additional range in Jason-1 and OSTM/Jason-2, respectively. Correcting for this further shortens the already short range measurements yet improves the agreement between Jason-1 and OSTM/Jason- 2 bias estimates (from +93 to $+212 \mathrm{~mm}$ for Jason-1, and from +172 to $+197 \mathrm{~mm}$ for OSTM/Jason-2, at the Bass Strait site). The cause of these anomalously high Jason-1 and OSTM/Jason-2 absolute biases is unknown and is still being investigated.

For Jason-1, when adopting the enhanced JMR product (Brown 2010) and maintaining the same processing approach of linearly extrapolating the wet delay (Figure 9), we observe an increase in the absolute bias by $\sim 11 \mathrm{~mm}$ (Figure 11). The same computation undertaken without the extrapolation procedure on the enhanced JMR data (i.e., the enhanced product is interpolated to the comparison point from the two points of closest measurement) increases the bias by $\sim 6 \mathrm{~mm}$ (standard deviation of $5.7 \mathrm{~mm}$, standard error about the mean $0.4 \mathrm{~mm}$ ). 


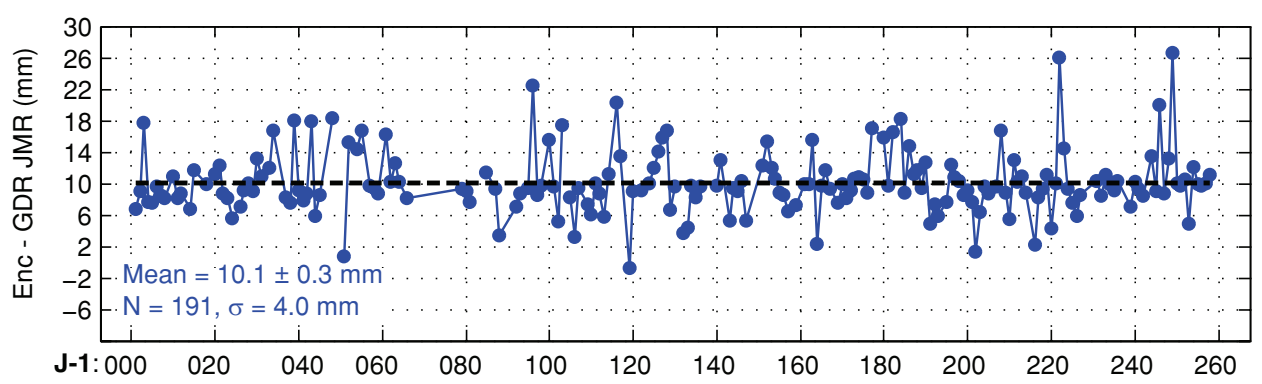

Figure 11. Relative SSH bias: Jason-1 enhanced JMR - GDR-C JMR. (Figure available in color online)

For OSTM/Jason-2, we see a smaller increase in the bias estimate when using the enhanced AMR product $(\sim 3 \mathrm{~mm}$, Figure 12). This increase reduces to $\sim 2 \mathrm{~mm}$ (standard deviation of $5.8 \mathrm{~mm}$, standard error about the mean $0.7 \mathrm{~mm}$ ) when the extrapolation method is not used for the enhanced AMR data.

Inspection of the cycle-by-cycle records of wet delay along pass 088 on approach to the Bass Strait comparison point show that the enhanced JMR and AMR products clearly outperform records taken from the existing GDR-C product, and that the extrapolation technique is probably not required. That our bias estimates agree to $\sim 6 \mathrm{~mm}$ and $\sim 3 \mathrm{~mm}$, respectively, confirms the appropriateness of the extrapolation technique for the GDR-C data. Further validation of these records against CGPS (as undertaken in Watson et al. 2004) has not yet been undertaken.

\section{Relative Bias}

Over the Jason-1 and OSTM/Jason-2 formation flight phase, common cycles may be compared to assess differences in various correction terms given that both altimeters were effectively sampling the same atmospheric and oceanic conditions (Figure 13). Mean differences in such corrections provide some insight into the relative contribution to observed differences in absolute biases between missions. Of interest, OSTM/Jason-2 senses less delay induced by the ionosphere $(+10 \pm 2 \mathrm{~mm}$, a known problem caused by an offset in the C-band range on OSTM/Jason-2) and more delay induced by the wet troposphere ( -5 $\pm 1 \mathrm{~mm})$.

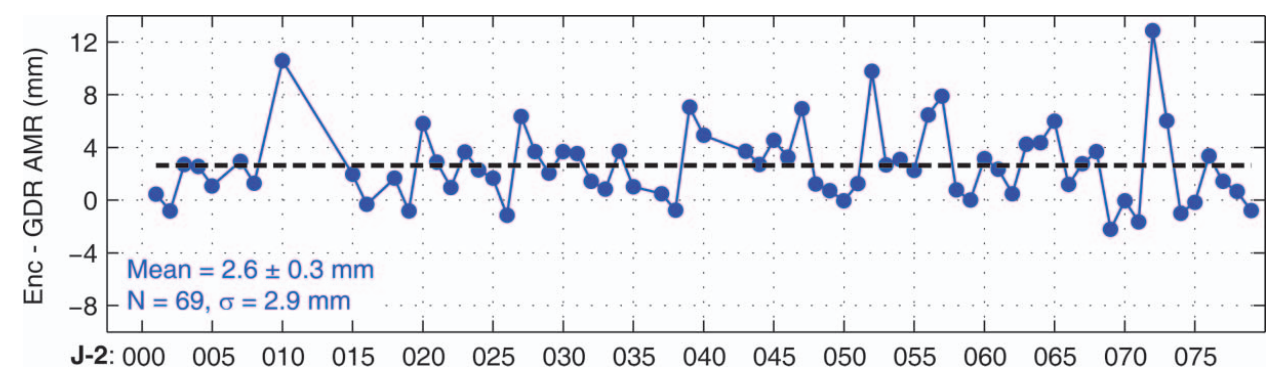

Figure 12. Relative SSH bias: OSTM/Jason-2 enhanced AMR - T/GDR AMR. (Figure available in color online) 


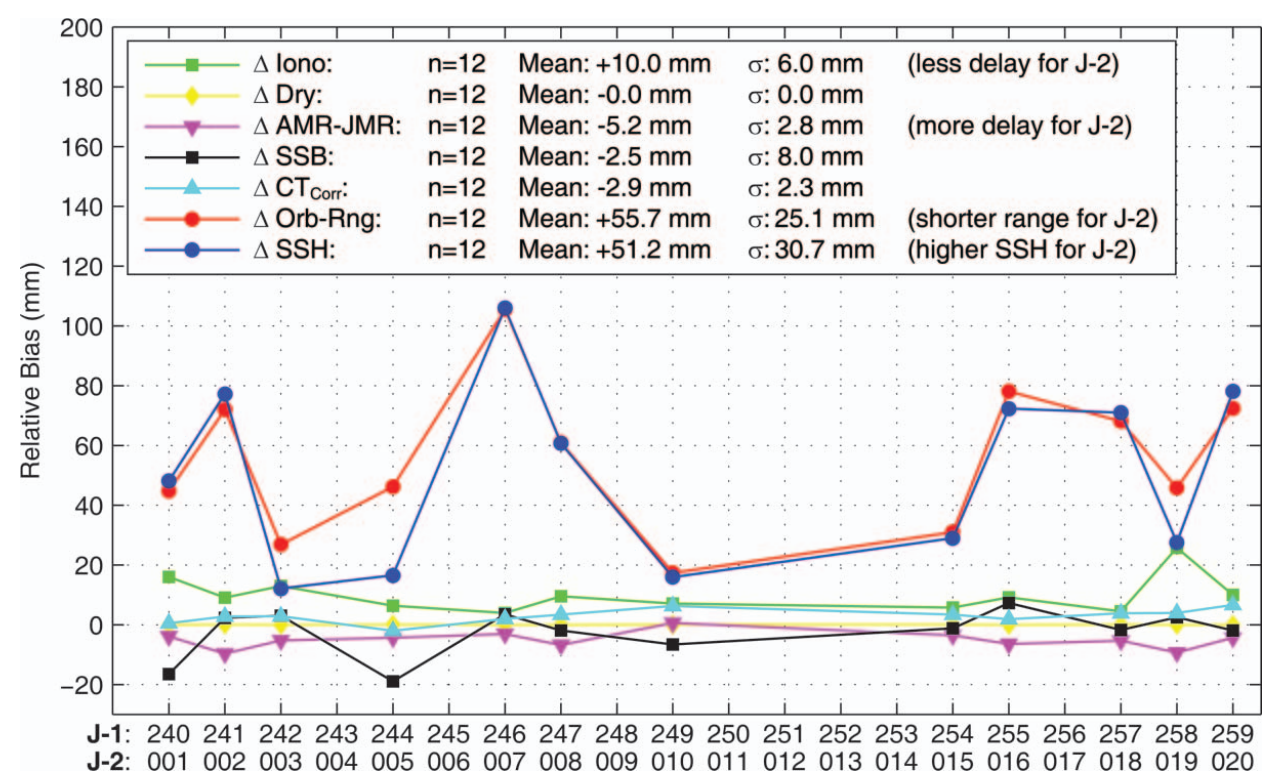

Figure 13. Relative bias and correction contributions for Jason-1 (J-1) and OSTM/Jason-2 (J-2) formation flight period (only common cycles shown), J-2 - J-1. (Figure available in color online)

The relative bias computed using common measurements of SSH over the formation flight was $+51 \pm 9 \mathrm{~mm}$. The difference in "orbit-minus-range" (i.e., removing the added influence from atmospheric, sea state and other corrections) was $+56 \pm 7 \mathrm{~mm}$. These estimates are low in comparison to Harvest and Corsica $(+80 / 82 \mathrm{~mm}$ and $+87 / 84$ for absolute bias/orbit-range, respectively; Haines et al. 2010; Bonnefond et al. 2010a). The Harvest and Corsica relative bias estimates are marginally higher than those derived from global analyses (e.g., $+76 \mathrm{~mm}$; Leuliette and Scharroo 2010).

Analysis of the complete bias time series from Bass Strait (Figure 10) shows that the Jason-1 bias during the formation flight period with OSTM/Jason-2 is marginally high (by approximately $20 \mathrm{~mm}$ ) compared with the mission average. When computing the relative bias between Jason-1 and OSTM/Jason-2 simply by differencing absolute bias estimates from the complete datasets (e.g., +172 minus $+93 \mathrm{~mm}$, Figure 10), the result of $+79 \mathrm{~mm}$ agrees with the global estimate of Leuliette and Scharroo (2010). The apparent structure within the bias time series during this formation flight period (and also evident at times within the TOPEX record) is currently under further investigation.

Noting that many of the non-time averaging components of the error budget relate to the datum (and are common across missions), the relative bias between missions or instruments can be determined far more precisely. The uncertainty in any drift in bias estimates reduces with increasing time and sample size, with a critical (and possibly dominant) error contribution being the uncertainty associated with the vertical velocity of the in situ tide gauge $( \pm 0.7 \mathrm{~mm} / \mathrm{yr}$ in this study). As the techniques to observe vertical land motion continue to improve, single in situ calibration sites such as Harvest and Bass Strait are likely contribute constructively to the determination of bias drift into the future. This issue will be further explored in future studies at this site. 


\section{Conclusions}

The Bass Strait calibration site employs a novel calibration strategy to allow the computation of cycle-by-cycle estimates of absolute bias on a descending altimeter pass in the southern hemisphere. Located in a tectonically benign area with little evidence for uplift or subsidence of the in situ instrumentation, the Bass Strait facility contributes a data stream that incorporates altimeter data back to the launch of TOPEX/Poseidon in 1992.

We estimate the absolute biases of TOPEX Side A and B to be $-15 \pm 20 \mathrm{~mm}$ and $-6 \pm 18 \mathrm{~mm}$, respectively, both insignificantly different from zero when assessed against the error budget. Jason-1 yields a bias of $+93 \pm 15 \mathrm{~mm}$, with OSTM/Jason2 having a bias of $+172 \pm 18 \mathrm{~mm}$. These bias estimates show exceptional agreement to those from the Harvest platform (to within formal standard errors about the mean), despite significant differences in wave climate between the experiment locations. To further assess the impact of sea state on our bias estimates, we have replicated the Bass Strait infrastructure in Storm Bay, located $\sim 350 \mathrm{~km}$ to the south east along pass 088. With increased exposure to the south west, Storm Bay experiences double the significant wave height to that of Bass Strait. Given identical instrumentation and methods of determining absolute bias at both sites, and highly correlated orbit errors, we seek to better understand the influence of sea state bias within the measurement loop using these two sites into the future.

That there remains unexplained absolute biases in both the Jason-1 and OSTM/Jason-2 missions underscores the complexity of the measurement system and the importance of calibration and validation activities that span successive missions and include a diversity of processing approaches and instrumentation.

\section{Acknowledgements}

Two anonymous reviewers are thanked for their constructive review of this manuscript. The contribution of this absolute bias data stream is supported by the Australian Integrated Marine Observing System (IMOS), established under the Australian Government's National Collaborative Research Infrastructure Strategy (NCRIS). The GPS data were computed on the Terrawulf II computational facility at the Research School of Earth Sciences, a facility supported through the NCRIS geoscience capability, AuScope Ltd. AuScope is also acknowledged for their support of regional CGPS installations used throughout this project. This paper is a contribution to the Centre for Australian Weather and Climate Research Climate Change Research Program. J.A.C. and N.J.W. were partly funded by the Australian Climate Change Science Program. The authors thank the International GNSS Service (IGS) and Geoscience Australia for making the raw GPS data publicly available, and the National Tidal Centre (NTC) for operating and maintaining the Burnie tide gauge with assistance from the Tasmanian Ports Corporation. The CSIRO Marine and Atmospheric Research coastal mooring group undertook the setup, deployment and retrieval of the mooring array. Neil Adams from the Australian Bureau of Meteorology provided atmospheric pressure information. Altimetry products were obtained from the Jet Propulsion Laboratory (JPL) PO.DAAC and Centre National d'Études Spatiales (CNES) AVISO archives. Members of the Ocean Surface Topography Science Team (OSTST) are thanked for providing ongoing technical assistance. Aspects of this work were supported under the Australian Research Council's Discovery Projects funding scheme (DP0877381). 


\section{References}

Altamimi, Z., X. Collilieux, J. Legrand, B. Garayt, and C. Boucher. 2007. ITRF2005: A new release of the international terrestrial reference frame based on time series of station positions and earth orientation parameters. Journal of Geophysical Research 112:B09401, doi: 10.1029/2007JB004949.

Benada, J.R. 1997. PO.DAAC merged GDR (TOPEX/POSEIDON) Generation B user's handbook, Version 2.0. JPL PO.DAAC 068.D002.

Bonnefond, P., P. Exertier, O. Laurain, and G. Jan. 2010a. Absolute calibration of Jason-1 and Jason-2 altimeters in Corsica during the formation flight phase. Marine Geodesy 33(S1):80-90.

Bonnefond, P., B. Haines, and C.S. Watson. 2010b. In situ absolute calibration and validation-a link from open-ocean to coastal altimetry. In Coastal Altimetry, S. Vignudelli, A.G. Kostianoy, P. Cipollini, and J. Benveniste (eds.), 259-296. Springer.

Brown, S., C.S. Ruf, and S.J. Keihm. 2002. Brightness temperature and path delay correction for TOPEX microwave radiometer yaw state bias. Technical Memo, August 8.

Brown, S., S. Desai, S. Keihm, and W. Lu. 2009. Microwave radiometer calibration on decadal time scales using on-earth brightness temperature references: Application to the TOPEX microwave radiometer. J. Atmos. Ocean. Tech. 26(12):2579-2591.

Brown, S. 2010. A novel near-land radiometer wet path-delay retrieval algorithm: Application to the Jason-2/OSTM advanced microwave radiometer. IEEE Transactions in Geoscience and Remote Sensing 48(4): 1986-1992.

Chambers, D.P., S.A. Hayes, J.C. Ries, and T.J. Urban. 2003. New TOPEX sea state bias models and their effect on global mean sea level. Journal of Geophysical Research 108(C10):3305-3312.

Geoscience Australia. 2011. Geodetic support for mean sea level (MSL) monitoring-Australia (ABSLMP), accessed November 2, 2011, http://www.ga.gov.au/geodesy/slm/abslmp/.

Haines, B., S. Desai, and G. Born. 2010. The harvest experiment: Calibration of the climate data record from TOPEX/Poseidon, Jason-1 and the Ocean Surface Topography Mission. Marine Geodesy 33(S1):91-113.

Herring, T.A., R.W. King, and S.C. McClusky. 2008. Introduction to GAMIT/GLOBK. Cambridge, MA: Massachusetts Institute of Technology.

Keihm, S.J., M.A. Janssen, and C.S. Ruf. 1995. TOPEX/Poseidon microwave radiometer (TMR): III wet troposphere range correction algorithm and pre-launch error budget. IEEE Transactions on Geoscience and Remote Sensing 33:147-161.

Lambin, J., R. Morrow, L. Fu, J. Willis, H. Bonekamp, J. Lillibridge, J. Perbos, G. Zaouche, P. Vaze, W. Bannoura, F. Parisot, E. Thouvenot, S. Coutin-Faye, E. Lindstrom, and M. Mignogno. 2010. The OSTM/Jason-2 mission. Marine Geodesy 33(S1):4-25.

Lemoine, F.G., N.P. Zelensky, D.S. Chinn, D.E. Pavlis, D.D. Rowlands, B.D. Beckley, S.B. Luthcke, P. Willis, M. Ziebart, A. Sibthorpe, J.P. Boy, and V. Luceri. 2010. Towards development of a consistent orbit series for TOPEX, Jason-1, and Jason-2. In DORIS Special Issue: Precise Orbit Determination and Applications to the Earth Sciences, P. Willis (ed.), Advances in Space Research 46(12):1513-1540, doi: 10.1016/j.asr.2010.05.007

Leuliette, E. and R. Scharroo. 2010. Integrating Jason-2 into a multiple-altimeter climate data record. Marine Geodesy 33(S1):504-517.

Menard, Y., L. Fu, P. Escudier, F. Parisot, J. Perbos, P. Vincent, S. Desai, B. Haines, and G. Kunstmann. 2003. The Jason-1 mission. Marine Geodesy 26(3-4):131-146.

National Tidal Centre (NTC). 2011. Australian baseline sea level monitoring project, accessed November 2, 2010, http://www.bom.gov.au/oceanography/projects/abslmp/abslmp.shtml.

Nerem, R., D. Chambers, C. Choe, and G. Mitchum. 2010. Estimating mean sea level change from the TOPEX and Jason altimeter missions. Marine Geodesy 33(S1):435-446.

Novatel. 2010. GrafNav kinematic and static GPS post processing software, V8.30. Novatel, accessed November 15, 2010, http://www.novatel.com/products/waypoint-software/waypointpost-processing-software/grafnav-grafnet/. 
Puri K., G. Dietachmayer, G. Mills, N. Davidson, R. Bowen, and L. Logan. 1998. The new BMRC limited area prediction system, LAPS. Australian Meteorological Magazine 47:203-223.

Ruf, C.S. 2000. Detection of calibration drifts in space borne microwave radiometers using a vicarious cold reference. IEEE Transactions on Geoscience and Remote Sensing 38(1):44-52.

Ruf, C.S. 2002. TMR drift—correction to $18 \mathrm{GHz}$ brightness temperatures revisited. Report to TOPEX Project, June 3.

Tregoning, P. and C.S. Watson. 2009. Atmospheric effects and spurious signals in GPS analysis. Journal of Geophysical Research 114:B09403, doi: 10.1029/2009JB006344.

Watson, C.S., R. Coleman, N. White, J. Church, and R. Govind. 2003. Absolute calibration of TOPEX/Poseidon and Jason-1 using GPS buoys in Bass Strait, Australia. Marine Geodesy 26(3-4):285-304.

Watson, C.S., N. White, R. Coleman, J. Church, P. Morgan, and R. Govind. 2004. TOPEX/Poseidon and Jason-1: Absolute calibration in Bass Strait, Australia. Marine Geodesy 27(1-2):107-131.

Watson, C.S. 2005. Satellite altimeter calibration and validation using GPS buoy technology. Doctoral thesis, Centre for Spatial Information Science, University of Tasmania, Australia. http://eprints.utas.edu.au/254/

Watson, C.S., R. Burgette, P. Tregoning, N. White, J. Hunter, R. Coleman, R. Handsworth, and H. Brolsma. 2010. Twentieth century constraints on sea level change and earthquake deformation at Macquarie Island. Geophysical Journal International 182(2):781-796, doi: 10.1111/j.1365246X.2010.04640.x.

Williams, S.D.P. 2008. CATS: GPS coordinate time series analysis software. GPS Solutions 12(2):147-153.

White, N.J., R. Coleman, J.A. Church, P.J. Morgan, and S.J. Walker. 1994. A southern hemisphere verification for the TOPEX/Poseidon satellite altimeter mission. Journal of Geophysical Research 99(C12):24505-24516.

Zaouche, G., J. Perbos, T. Lafon, V. Couderc, J. Lambin, J. Desjonqueres, C. Jayles, E. Jurado, P. Vaze, L. Fu, S. Brown, F. Parisot, H. Bonekamp, W. Bannoura, and J. Lillibridge. 2010. OSTM/Jason-2: Assessment of the system performances (ocean surface topography mission: OSTM). Marine Geodesy 33(S1):26-52. 